\title{
AC 2011-1508: UNDERSTANDING MEXICAN FACULTY DESCRIPTORS OF ENGINEERING USING METAPHORS TO HELP EXPLAIN GENDERED BOUNDARIES
}

Silvia Carreno-Castillo, Universidad de las Amricas Puebla

Aurelio Lopez-Malo, Universidad de las Americas Puebla

Enrique Palou, Universidad de las Americas Puebla

Enrique Palou is Director, Center for Science, Engineering, and Technology Education; and Professor, Department of Chemical, Food, and Environmental Engineering at Universidad de las Americas Puebla in Mexico. He teaches engineering design, food science, and education related courses. His research interests include emerging technologies for food processing, creating effective learning environments, and building rigorous research capacity in science, engineering and technology education. 


\section{Understanding Mexican Faculty Descriptors of Engineering Using Metaphors to Help Explain Gendered Boundaries}

\section{Introduction}

A major theme in the literature regarding women in science, technology, engineering, and mathematics (STEM) fields concerns the construction of STEM as a masculine dogma. Past research suggests that women's previous exclusion and persistent under-representation is rooted in the construction of science as rational, objective, neutral and in opposition to traditional notions of femininity or alternative modes of masculinities ${ }^{1,7,12,13}$. Being included, as man or woman, in the object that we are trying to comprehend, we have embodied the historical structures of the masculine order in the form of unconscious schemes of perception and appreciation. When we try to understand masculine domination we are therefore likely to resort to modes of thought that are the product of domination ${ }^{2}$. Nowadays, the studies about the underrepresentation of women explore the idea of individual and institutional barriers women face by focusing on their direct experiences, however this paper will center the attention to the boundaries from engineering faculty members. Further, it suggests ways that the idea of boundaries can help analyze the content and ideas that define engineering these days, and investigate whether the conceptual borders of engineering itself could be considered as having gender-based distinctions. This research provides a different perception of how boundaries can be interpreted in engineering, how engineering faculty members in Mexico engage in these boundaries, which will help us understand the socially-influenced choices that determine who can be engineers and what engineering is.

Pawley ${ }^{11}$ mentions that in the United States most of the programs designed to address women's persistent underrepresentation in STEM disciplines employ "pipeline" or "chilly climate" metaphors, or a combination of the two. Programs that employ this model attempt to "increase the flow" of those underrepresented populations into the inlet by increasing access to scientific and technical programs, and plugging the aforementioned leaks. Chilly climate-based models suggest that a "chilly environment" that discourages people already under environmental stress causes the leaks. In other words, Pawley assures that these programs, which help to stem these leaks, provide metaphorical "sweaters" - "survival tools" for underrepresented populations to better withstand the chilly environment - or train their white male peers on how to increase the "thermostat" by implementing, for example, parent-friendly tenure procedures, gender-neutral hiring protocols, or the much-maligned idea of "sensitivity training"11.

In Mexico, over the past three decades, have been produced a series of social transformations that relate, among other factors, with the increase of women into the workforce and education. These facts have been overturned or at least questioned, in many social sectors, the tasks between men and women. Most of the research work in Mexico related to the underrepresentation of women in the engineering field, has been done through the analysis of the historical factor of the development of education, the patriarchal structure of the first programs opened to women, and the cultural believes of the nature of women's work. Nevertheless, Mexican public universities have done an effort to create specific strategies to incorporate more female students and professors to the universities ${ }^{4-6,8}$. 
According to the French sociologist, Pierre Bourdieu, schools [individuals] value and reward the cultural capital of the dominant culture and devalue that of students from subordinate cultures, this means that students and professors bring with them to school some inculcated dispositions that are of vital importance in their interactions with each other. Therefore, "the contribution made by the educational system to the reproduction of the structure of power relationships and symbolic relationships between classes, by contributing the reproduction of the distribution of cultural capital among these classes" is essential in understanding the role of education in buttressing divisions within classes $^{3}$.

While these explanations have helped to assemble conceptual components, they leave some concepts without an answer: how we define "engineering" and how we use "gender" as a category to understand women's underrepresentation in engineering. In order to give an answer to these concepts we utilize the construct of "boundary-work", which describes an ideological style found in scientists' attempts to create a public image for science by contrasting it favorably to non-scientific intellectual or technical activities. Alternative sets of characteristics available for ideological attribution to science reflect ambivalences or strains within the institution: science can be made to look empirical or theoretical, pure or applied. However, selection of one or another description depends on which characteristics best achieve the demarcation in a way that justifies scientists' claims to authority or resources. Thus, "science" is no single thing: its boundaries are drawn and redrawn in inflexible, historically changing and sometimes ambiguous ways ${ }^{9}$. A boundary is not a physical thing in this context, but an idea that researchers can use as a tool to understand people's experiences. It is not a defined "line" but, rather, is located along the margin of a clump of accepted practices; this edge may be determined differently by different people ${ }^{11}$.

As we mentioned before, Bourdieu and more recently sociologists of science have argued that the historical boundaries of education (engineering education) incorporate a group of accepted practices defined by socially influenced notions of "men's work" and "women's work." 2, 3, 10 . If we want to understand women's underrepresentation in engineering in our country, it is necessary to explore new dimensions, which give us the true reality of what happens inside the engineering culture in Mexican universities, that is the reason to consider where academic engineering's boundaries are today by asking us how do modern engineering faculty members understand, influence, reproduce, or resist engineering's historically gendered boundaries? This paper describes results from an interview-based study of both men and women engineering faculty members at a small, private, and research-oriented university in Mexico, focusing on how faculty implicitly or explicitly describe the boundaries of engineering, and how their descriptions reproduce or resist historically-influenced ideas about women's and men's work.

\section{Difficulties and potential uses of the category of gender as an analytical unit}

American feminism prompted the use of the category of gender in the 1970's with the intention to differentiate social and cultural constructions of the biological facts. In addition, to the scientific goal of understanding social reality, with the sole intent to point out that human characteristics considered "feminine" were acquired by women through a complex individual and social process, rather than derived "naturally" from their own sex. The concept of gender inside engineering education has tended to presume that the correct scale to use, measure, and 
record "gender" is one of the a dichotomous categories "male" and "female." It is undeniable that there are biological differences between people defined or identifying as males or females, however, it is necessary to recognize that such "differences" have been built and repeated collectively by the society throughout its particular history and culture.

Pawley ${ }^{11}$ says that the definition given above, help us to assert the belief that ideas and objects, as well as people, can have gender based distinctions, "gendered", in cases where the impact of such ideas, objects or processes are differentially experienced by people of different genders. For example, a hairbrush may be considered "gendered male" through its design, packaging, and marketing in order for it to be used disproportionately by men. A job may be "gendered female" through its design, resource allocation, and requirements for success in order for disproportionately more women to succeed in it than men. However, gendering need not be intentional to have an important impact. The data of this paper will use gender as a category of analysis based on symbols that construct gender, social rules, which make use of these symbols, and power relations that are constructed from such social rules ${ }^{11}$.

\section{Methodology}

Two research questions investigated in this qualitative study are:

1. Can a boundary metaphor aid in understanding engineering faculty members' explicit or implicit descriptions of engineering or their discipline within engineering?

2. How do faculty members' descriptions interact with historically and socially influenced ideas about women's and men's work?

Ten engineering faculty members were interviewed from a small Mexican private institution of higher learning committed to first-class teaching, public service, research and learning in a wide range of academic disciplines including business administration, the physical and social sciences, engineering, humanities, and the arts. These faculty members were selected from a pool of potential participants using maximum variation (including disciplines, faculty ranks, administrative roles, and gender). Of the selected and invited faculty, none refused to participate. Interviews were semi-structured and lasted on average 90 minutes each.

The pilot-tested interviews were semi-structured and usually were conducted over two periods of 45 minutes each, although the total time varied from 90 to 100 minutes. Questions having to do with defining engineering, identity, and research were included in the first interview, while questions having to do with teaching, service and gendered disciplines were asked in the second.

Following Pawley ${ }^{11}$ interviews were transcribed and first coded with broad codes associated with the study's research questions, namely "engineering identity," "defining engineering," "pressure agents," "boundaries," and "gender." For this paper, text that was coded as "boundaries" was reanalyzed with a set of finer-grained codes that emerged from the data. Examples from this subset of fine-grained codes will be presented in the following section. 


\section{Results and discussion}

In general, male participants expressed more opinions on engineering identity, defining engineering and pressure agents, while female participants extended their views on engineering identity, gender, and boundaries.

\section{Boundary language}

We analyzed faculty members' interview responses for language associated with "boundary" metaphors that yield a rich lexicon of terms related to the complicated characterization and categorization of ideas and values associated with engineering ${ }^{11,14}$.

Some of the faculty members' language explicitly expresses the idea of boundaries: Two full time laboratory professors described they felt that their work was undervalued because their classes are not theoretical on their idea of boundaries within the school of engineering:

"Here is a very strong tendency to consider lab classes as a lower degree or not as important as the theory ones, being a professor of laboratory does not mean we do not have the capacity to lecture a theory class, but we believe that we are not given the same opportunity that is given to the theory teachers. Deans do not believe in us because they think that our classes are simple workshops, they do not see the importance of laboratory experiences in the development of students."

Another example is from a full professor describing the boundary of having students from different economical and educational status:

"Having a group in which the level of academic preparation is very different, makes students to face problems such as not having the necessary knowledge and skills in math, language, working with tools or machinery, or just knowing the characteristic lingo of this engineering discipline. I have had students that decided to switch careers, because they think that engineering is not for them, while in other cases their parents forced them to study engineering when in fact they had wanted to be designers or lawyers"

This faculty member talks about the difficulty of some students to work or interact with some other disciplines inside and/or outside the engineering school:

"The majority of the faculty of the engineering school is specialized in a specific discipline, so some students have difficulties working together with students from another discipline, for example last semester I taught a class in which I had the opportunity to work with three different disciplines of engineering, at the beginning of the class the teams and participations in class was divided into their areas of expertise, however I explained the whole class that they didn't have to have this o that knowledge, so they could stay. I remember that one of the students complained that her team was excluding her in the development of the class projects because she was studying industrial engineering... they set a meeting time and suddenly it was changed without notice, etc." 
Three of the ten teachers interviewed perceived that most teachers, who teach theory classes, underestimate the laboratory area, considering that what is taught in the laboratory is less important than the theoretical base. Eight out of ten teachers feel that some of their new students are often discouraged or even leave the degree, arguing lack of language skills and the prior knowledge necessary to stay in that particular engineering discipline.

Everyone of the professors, during their student's days, did not identify any language barrier between their teachers and them, however, female professors identified during this period that they had to adapt to the modus operandi of their male classmates, nevertheless, they clarified that they were not verbally or nonverbally disrespectful to them. A teacher mentioned that the communication within the classroom between male and female students is very different; she explained that due to the cultural influence, men are more exposed to the engineering issues since childhood, while Mexican culture alienates women from areas related to construction, mechanics, motors, and even mathematics. It is for this reason that this teacher pays more attention to their female students, especially during their first semester to better understand the language and the environment of engineering.

These interventions suggest that Mexican faculty already think of both their specific discipline and the broader notion of "engineering" in terms that can be understood through a boundary metaphor. In the next section, we explore trough their personal experiences (as an engineering student and as a professor) how their academic practice helps to define, recognize, resist, or reproduce engineering's perceived boundaries.

\section{Boundary work}

Gieryn", defined boundary-work as the "attribution of selected characteristics to an institution (i.e., to its practitioners, methods, stock of knowledge, values, and work organization) for purposes of constructing a social boundary that distinguishes some intellectual activities as outside that boundary.

Faculty members expressed a clear idea about the types of intellectual and collaborative "work" done within their own department in order to contribute to the goals or expansion of their "disciplinary space". A full professor described the strategic planning that his department had engaged, and used in a first year class that works at the same time theory, modeling and laboratory experiences by means of specific design projects:

"At the beginning it was difficult to believe that students from six different engineering majors would work together, and especially if the class was given by three different professors with diverse backgrounds, fortunately the experience taught us the importance of working as a multidisciplinary team not only at the students level, but also at our level."

Another professor, told us how important was for him to establish a boundary between the administration and the academy:

"I remember when I was called by the administration to say that a particular company was interested in donate laboratory equipment, they were ready for me to sign and accept the 
material that the company was sending. However, the school of engineering was trying to give each of our students the best preparation, so by having two or three engines, or a full car body was not going to help my department, so proposed them if as a faculty we could work on a list of things that truly will impact our educational program."

A final example of boundary work is evident in one full professor's description of some work he has been doing:

"Years ago, I used to take some of my student to the USA, in order to expose them to the real work [experimental work] of the industry, but due to the economical situation of the country and of course of the institution, I decided to find new ways to show my students the importance of combining the theoretical and the experimental components. When I enter the university we didn't had the laboratories we have now, for each theory class we have its own lab. I really want my students to have their hands on all the time, we are engineers and we have to solve problems, so this shouldn't change."

In general, interviewed teachers agreed that students' difficulties working with other engineers are only at the beginning of the program. Teachers report that these barriers are more common in schools that tend to mix different areas of expertise. Also, the teachers agreed there is a very collaborative environment among colleagues and engineering disciplines. However, eight out of ten teachers said that there is a lack of coordination between the academic and administrative areas, specifically because there is no deep knowledge about the real needs of students and their curricula. Seven out of ten teachers recognized that for the ideal development for students of engineering, we need more and better partnerships with different sectors of industry in order for engineering students to develop and implement what they learned in the classroom, resulting in better-qualified engineers.

On the other hand, five teachers reported that since their time as students, teaching methods and practices have changed dramatically, during that time most of their teachers used to work in industry and taught at the university, so that the contact between student-professors outside the classroom was almost nonexistent. Nowadays, the teacher-student relationship is cordial, friendly and casual. They also mentioned that the actual generation compared to theirs has more access to laboratories and practices.

This section described the ideas of boundary language and work and provided some illustrative quotes from faculty members. The next section argues that the boundary metaphor can be used to make visible the gendered character of engineering.

\section{Looking for the differences and stereotypical gender roles in engineering}

The second research question for this paper focuses on how engineering faculty members' descriptions of engineering can be understood through gender analysis. The conceptual tool of a boundary can aid in this exploration as the idea of a boundary denotes zones of inclusion and exclusion, and the consideration of a "boundary" in analyzing the profession of engineering makes one to look for what areas are included as well as from those that are excluded ${ }^{11}$. 
This section includes some thoughts on engineering's historical development, and the "problems" engineers have tended to focus on, both of which are structured by dichotomies of "women or men" work. As an example of the impact of history on engineering's disciplinary boundaries in Mexico, a full professor expressed:

"One of the reasons why women do not study engineering is historical, when the engineering education began in Mexico, women didn't even had the right to education, and the first engineering program was Mining a work that wasn't suitable to women, culturally we were not prepared to see women outside their houses, but the economical situation has forced then to openly seek for jobs that were mainly for us."

Another two professors mentioned that one of the boundaries for women to study mechanical engineering is the misconception of the field:

"Not everything about mechanical engineering is oil, dirt and cars, it seams that we are confused with car mechanics, our field I believe, is much more broader than women think."

On the same tone, other professor mentioned:

"A few days ago, a girl student told me that she was very worried about her skills because she felt that she didn't have the capacity of her male classmates. I told her that is not about strength, or ability with hands but it's about persistence and approaching teachers to ask and solve her doubts, Mechanical engineering can give you the opportunity to work in different fields, is not just about cars."

In a different example, a full professor argued that women who study engineering have to redefine their lives if they want to have family. This participant said:

"When I started working on the industry I never thought that I could change what I was doing at that time, especially because the payment was really good, but I had to step back and analyzed what kind of life I wanted for me, it is hard to find a good husband or have a child in the middle of nowhere, so I quit my job and after a time-off, here I am teaching an enjoying my life as women, I must accept that I sometimes miss a lot the field and the corresponding adrenaline."

One hundred percent of the population of teachers interviewed agreed that there is no evidence that barriers exist within or outside the academy, everyone agrees that the low number of women in engineering programs is due to the culture of this country that encourages men to study degrees that are more related to mathematics, construction, electricity, etc., to think that thrive in very hostile to women. In addition it is much more practical to promote careers for women to enable them to raise a family without compromising their physical integrity.

It is certainly disturbing, that generations of young parents continue transferring specific stereotypes for men and/or women, if such stereotypes were changed from home, they would not exist inside or outside of our educational, social, political, industrial, etc., practices. 


\section{Final remarks}

As we mentioned at the beginning, this paper utilizes the boundary metaphor as a tool to explain women's underrepresentation in engineering. In this case we try to explain through this phenomena by analyzing the concepts of "gender" and "engineering". Without a doubt the boundary metaphor has helped us to make visible the reflecting gender differences and gender roles of engineering while making explicit the language that engineers utilize, the type of work they perform, and the challenges they are facing.

Finally, we have to make an effort to become more aware of those non spoken images and actions that we transfer to our students, because it is clear that using those practices we tend to include or exclude, and reproduce the system; most of the time unconsciously.

\section{Acknowledgments}

Author Carreño-Castillo gratefully acknowledges financial support for her doctoral studies from the National Council for Science and Technology (CONACyT) of Mexico and Universidad de las Américas Puebla.

\section{Bibliography}

1. Blackstone, T. and Weinreich-Haste, H. (1980) Why are there so few women scientists and engineers? New Society, 51: 383-385.

2. Bourdieu, P. (2000) La Dominación Masculina, traducido por Joaquín Jordá. Editorial Anagrama, España,

3. Bourdieu, P. and Passeron, J. C. (1977) Reproduction in Education, Society and Culture. London: Sage.

4. Blazquez, N., Bustos, O. and Gandarilla (2005) La Inequidad de Género en la UNAM. Análisis y Propuestas. México: UNAM.

5. Blazquez, N. and Flores, J. (2005) Ciencia, Tecnología y Género en Iberoamerica. México: UNAM.

6. Blazquez, N. and Bustos, O. (2003) Qué Dicen las Académicas Acerca de la UNAM. México: UNAM.

7. Faulkner, W. (2000) The power and the pleasure? A research agenda for 'making gender stick' to engineers. Science, Technology and Human Values, 25(1): 87-119.

8. García, P. (2004) Mujeres Académicas. El Caso de una Universidad Estatal Mexicana. México: P y V Editores.

9. Gieryn, T. F. (1983) Boundary-work and the demarcation of science from non-science: strains and interests in professional ideologies of scientists. American Sociological Review, 48(6): 781-795.

10. Olmsted, J. (2001) Men's work/women's work: Employment, wages and occupational segregation in Bethlehem, Research in Middle East Economics, 4: 151-174.

11. Pawley, A. (2007) Gendered boundaries: using a "boundary" metaphor to understand faculty members' descriptions of engineering. Proceedings for the 37th ASEE/IEEE Frontiers in Education Conference, Milwaukee, WI.

12. Rosser, S. V. (1998) Applying feminist theories to women in science programs. Signs: Journal of Women in Culture and Society, 24(1): 171- 201.

13. Stepulevage, L. and Plumeridge, S. (1998) Women taking positions within computer science. Gender and Education, 10(3): 313-326.

14. Upchurch, M. (2006) Women in the Brain: A History of Glial Cell Metaphors. Presented June 16 at the National Women's Studies Association Conference, Oakland, CA. 